\title{
The Exploration on the Local Engineering Colleges Enrollment Mode under the Background of the National College Enrollment System
}

\author{
Zhao Yejiong $^{1, a}$, Zhu Bei ${ }^{1, b,{ }^{*}}$ and Tang Zhengqin ${ }^{1, c}$ \\ ${ }^{1}$ Shanghai University of Engineering Science, Songjiang,Shanghai,China \\ azhaoyejiong@sues.edu.cn, bzhubei124@126.com, ctangzhengqin@sues.edu.cn \\ ${ }^{*}$ Corresponding author
}

\begin{abstract}
The College entrance examination system is an important system related to the future and destiny of a nation. The Third Plenary Session of the 18th Central Committee of the Communist Party of China determines to deepen the reform of the college entrance examination and enrollment system, which plays an important role in promoting the scientific selection and the development of students and maintaining the fairness of education. Based on the background of the reform of national college entrance examination and enrollment system, this paper analyzes the way of local engineering colleges and universities choose to change the traditional recruitment model and make a conclusion with the research in order to promoting the development of the reform of the college entrance examination.
\end{abstract}

Keywords: College Entrance Examination, Reform, Local Engineering Colleges, Enrollment Mode.

\author{
国家高考招生制度改革背景下的地方工科类高校招生模式探究 \\ 赵晔照 ${ }^{1, a}$, 朱蓓 $2, b,{ }^{*}$,汤正琴3,c \\ ${ }^{1}$ 上海工程技术大学, 松江, 上海, 中国 \\ azhaoyejiong@sues.edu.cn, bzhubei124@126.com, ctangzhengqin@sues.edu.cn \\ *通讯作者
}

中文摘要.高考招生制度是涉及国家前途命 运的重要制度。党的十八届三中全会决定全 面深化高考招生制度的综合改革, 对加强高 考招生制度在推进科学选人、促进学生发 展、维护教育公平有着重要作用。本文以国 家高考招生制度改革为背景, 就地方工科高 校在此背景下如何改变传统招生模式进行
探讨并得出研究结论, 为加快高考招生考试 改革奠定基础。

关键词:高考招生;改革;地方工科类高校; 招生模式 


\section{1. 引言}

自1977年我国恢复高等学校招生考试 制度以来, 这一利国利民的决策使超过 1 亿 中国人踏入高等学校接受高等教育, 数千百 万家庭的命运因高考而改变。通过三十多年 的不断改进和完善, 我国形成了相对完备的 高等学校招生考试体系, 为国家的跨越式发 展做出了历史性贡献。经过 30 多的考验, 高 考作为我国长期坚持的选拔人才途径因其 权威性、公平性基本得到社会的认可。

随着国家经济社会的飞速发展,一方面 人民群众对教育提出了更高的要求, 另一方 面社会对高素质人才的需求也日益迫切。但 是目前实行的高等学校招生考试制度由于 其在人才评价标准、招考选拔方式等方面的 缺陷, 使 “一考定终身”、重分数轻能力 的现象仍普遍存在, 通过高考选拔高素质人 才的目标仍未达成。如何通过完善高等学校 招生考试制度更好地推进科学选才、更好地 促进学生全面发展、更好地维护社会公平正 义正成为教育界亟需思考和解决的问题

而党的十八届三中全会出台的《中共中 央关于全面深化改革若干重大问题的决定》 提出解决的方案: “推进考试招生制度改革, 探索招生和考试相对分离、学生考试多次选 择、学校依法自主招生、专业机构组织实施、 政府宏观管理、社会参与监督的运行机制, 从根本上解决一考定终身的弊端。推行初高 中学业水平考试和综合素质评价。逐步推行 普通高校基于统一高考和高中学业水平考 试成绩的综合评价多元录取机制。探索全国 统考减少科目、不分文理科、外语等科目社 会化考试一年多考。”[1]

\section{2. 高考招生制度改革的特点}

\section{1 选人理念的变化}

高考招生制度的改革本质上是国家选 拔人才理念的变化。随着经济全球化和信息 化时代的来临, 国家对人才的选拔理念已从 过去的选拔专业型、区域性人才转变为选拔 复合型、全球化人才。高考招生制度作为国 家选拔人才的根本性制度应以满足未来国 家人力资源发展需求为目标, 以遵循教育发 展规律和人才培养规律为基础, 以促进学生
成长成才和全面发展为突破口, 不断适应国 家选人理念的变化。

\section{2 招考模式的变化}

高考招生制度的改革关键在考试模式 和招生模式的变化。实践证明, 以往高考招 生模式虽然能快速为国家选拔大量人才, 但 其一元化的考试模式和录取模式既不利于 学生的全面发展和个性化培养, 也不利于不 同层次、不同特色高校选拔到合适本校培养 模式的学生[2]。此次考试招生制度改革通 过改变招考模式, 强化分类考试、综合评价 和多元录取机制, 既增加了学生的选择性、 分散了高考压力, 也增加了高校招生的选择 性、科学性, 为高校开展 “因材施教” 奠定 了良好基础。

分类考试就是将普通高校招生考试和 高职院校招生考试分开, 加强应用型高校和 高职院校普通高校对学生的综合技能考察, 满足不同层次学校对人才选拔的特定需求。 在高考命题方面将着重考查考生运用所学 知识独立思考与分析问题、解决问题的能 力。

综合评价就是开展高中学生综合素质 评价, 改变以往只重理论学习成绩的评价方 式, 建立覆盖德智体等全方位的学生评价体 系, 并通过将评价结果直接作为学生毕业和 高校招生的重要参考, 引导学生做到品学兼 优、全面发展和培养个性特长。

多元录取就是改变目前“一套考卷看高 低” 和 “一次考试定终身” 的单一制高考录 取模式。一是通过引入体现学生日常综合素 质的高中学业水平考试, 扩大高校对学生的 观察面, 降低学生的日常考试压力。二是增 加学生的考试机会, 在以往开展春季高考的 基础上, 扩大春季高考的录取范围和高校质 量, 允许应届生参加春季高考, 尝试一个学 生被多所高校录取, 给学生多方面的选择 权。三是扩大学校的招生自主权,借鉴美国、 日本等西方发达国家经验, 逐步实现招考分 离。

\section{3. 高考制度改革}

高考招生制度改革是一项复杂的系统 工程, 需要通过科学筹划和不断试点完善才 
会取得成功。上海、浙江作为教育较为发达 的地区被教育部列为试点地区, 从2017年开 始实行新的高考制度。两省随即出台了相应 的实施方案。

\section{1考试科目}

在上海和浙江的试点方案中, 高考的考 试科目的设置由原先的 “ $3+1$ ”, 变为了 “ $3+3$ ”并引入了普通高中学业水平考试。 高中学业水平考试的考试科目为13项, 涵盖 了高中所有应学科目。

\section{2考试时间}

在考试时间安排方面, 上海和浙江方案 存在较大差异。上海将高中学业水平考试各 科目考试的时间跨度分为高中三年, 实行 “随教随考随清”的考试制度。这不仅有利 于高中根据自身实际合理分配教学资源, 也 利于减轻学生的日常学业负担。而浙江将高 中学业水平考试一年安排两次, 分别在 4 月 和10月进行。

\section{3考试成绩}

上海高考成绩与浙江考试成绩构成形 式相同，既从2017年起，高考成绩由语文、 数学、外语 $3 门$ 统一高考成绩和学生自主选 择的普通高中学业水平 $3 门$ 等级性考试科目 成绩构成。

\section{4. 招生录取模式改革}

考试制度的变革必然带来招生模式的 变革。在此次高考改革试点过程中, 无论是 上海方案还是浙江方案都对高校改进招生 录取工作提出了新要求。各高校尤其是地方 普通高校都应做好充足的准备, 以把握高考 招生制度改革的良机。以典型的面向全国招 生的地方工科类高校一一上海工程技术大 学为例, 需要通过努力提高生源质量、科学 设置报考科目、积极改进招生程序等途径不 断提升人才选拔的质量。

\section{1学校生源挑战}

作为上海地方应用型工科高校, 上海工 程技术大学以往只能参与第二批次招生。但 是此次高考招生制度改革明确了第一、二批
本科合并招生的方案, 这就为学校招生工作 提供从所未有的机遇和挑战。

学校得到的机遇是: 高校的生源选择面 有所扩大。学校首次有机会与众多 “985”、 “211” 等重点高校同场竞技, 以往受制于 批次限制而无法获得高分生源的情况将有 所改观。学校虽然只是一所地方性工科院 校, 但得益于学校长期坚持的学科链、专业 链对接产业链、技术链的办学理念和产学合 作教育人才培养模式, 已经拥有一批在上海 乃至全国都享有声誉的学科和专业, 其中汽 车、航空运输、飞行技术、轨道交通等产学 合作办学专业更是由于与上海相关产业行 业紧密结合、开设该专业的院校少、毕业后 就业率高等特点受到广大学生和家长的青 睐。

学校面临的挑战是: 上海地方高校的招 生竞争将日趋激烈, 招生压力日益增大, 特 别是一些招生人数较多、就业前景不明的专 业可能会出现生源人数锐减的情况。造成这 一情况的原因是多方面的: 一是具有参加高 考资格的上海户籍人口持续负增长, 近 5 年 来上海地区高考生源人数呈显著下降趋势, 2010 年上海高考人数为 6.7 万人, 2014 年下 降至 5.2 万人; 二是当前高中学生的升学方 式选择趋向多样化, 部分家庭选择让学生高 中毕业后直接赴海外接受高等教育; 三是伴 随地区经济转型和结构调整, 越来越多的基 础制造业转移至全国其他地区乃至海外, 相 关工科专业学生毕业后在沪就业的机会日 趋减少; 四是上海高校部分专业设置重合度 高, 尤其以管理类、社科类专业较为普遍, 相关人力资源市场呈现供大于求的情况, 阻 碍了学生的报考热情。而艺术类专业由于受 就业面窄、取消艺术类加分政策等不利因素 影响, 未来生源数量也将逐渐减少。

\section{2 专业科目设置}

学校作为一所地方性应用型工科高校, 专业分布以传统的机械、电子、材料、化工 等传统工科为基础, 以产学研合作办学的汽 车、航空运输、飞行技术、轨道交通等特色 工科专业为特色, 并涵盖了管理、社会科学、 艺术、服装、多媒体设计等非工科专业, 本 专科专业总数达到 85 个。从学科特点和专业 要求为出发点, 工科专业由于具有较强的专 
业性对学生的逻辑思维能力、理科知识储 备、实践动手能力等具有较高的要求, 因此 在报考科目设置方面应以物理、化学、生物 等传统理学学科为主。而非工科专业更注重 学生的综合素质、人文修养和创新思维, 因 此在报考学科方面可考虑不作限制, 为学生 提供广泛的选择。

\section{3 招生录取程序}

公平公正公开是高校招生工作的生命 线。依法开展高考招生工作, 实现高考招生 的法治化、程序化、透明化是教育主管部门 和各高校努力的方向。地方工科高校在开展 高考招生录取工作时应着重建设和完善一 下工作机制:

一是完善招生录取工作的合法信息披 露机制。招生信息披露是高校招生工作的重 要环节, 也是让社会知晓高校招生过程的重 要途径。随着互联网和自媒体技术的迅速发 展, 高校招生的信息披露媒介已从传统的线 下披露转变为线上线下同步披露、以线上披 露为主。地方高校应加强招生信息化建设, 充分利用信息化手段将涉及高考招生的各 项依法可以公开和应该公开的内容及时向 全社会及时公布, 确保广大人民群众的知情 权, 确保高校招生工作的公开性。

二是形成招生录取工作的集体科学决 策机制。招生是高校人才培养工作的第一 环, 也是高校的核心工作之一, 形成一套科 学、完善的招生工作决策机制对做好高校的 发展具有重要意义。多年的实践证明, 采用 民主集中的决策方式能够有效确保决策的 公平公正。因此作为地方工科高校应在上级 教育主管部门的指导下通过建立学校招生 委员会等方式确保招生工作中的决策民主 并由学校行政负责人一一校长对决策结果 负责。

三是加强招生录取工作的全过程监督 机制。缺乏监督的权利必然会导致公平公正 的缺乏。多年来, 高校招生工作已成为发生 权钱交易等腐败现象的重灾区。为保证高校 招生工作的严肃性、公正性, 无论是部署高 校还是地方高校都应积极发挥校内和校外 两方面的作用。在校内, 一是应充分发挥纪 检监察部门的监督作用, 使纪检监督工作贯 穿高校招生工作的全过程, 特别是在涉密工
作、利益人员回避、影像监督等方面发挥作 用; 二是要形成建立各参与部门相互制约、 相互监督的局面, 形成集体共同监督的良好 局面。在校外, 则可以积极引入第三方资源, 加强对高校招生全过程的监督, 例如可以在 不违反国家法律和考试规定的基础上, 邀请 社会贤达、考生家长代表等观摩招生录取过 程, 实现招生工作的透明化。

四是建立招生录取工作的申诉问责机 制。申诉和问责是保证招生录取工作公平公 正的最后环节。高校应建立行之有效的、贯 穿招生录取全过程的申诉、调查、回馈、问 责制度，快速、准确、积极地回应考生、家 长及社会各界对于学校高校招生录取方面 的疑问、投诉, 特别是要重视事前和事中的 申诉调查工作, 将在招生录取工程中可能发 生的风险遏制在萌芽阶段。

\section{5. 未来改革与挑战}

中国的高考招生制度改革的最终目标 是实现招考分离、多次选择。当前, 无论是 上海方案还是浙江方案只是高考招生制度 改革的 “最先一公里”。未来, 我国的高考 招生制度改革将改变目前的“全国统一通过 高考招生” 形式向着学生有多次考试机会、 录取学校有多次选择选择机会、学校依法开 展自主招生的方向大步迈进。对于缺乏自主 招生工作经验的地方工科高校而言, 学习国 内外高校先进经验, 探索适合本高校办学特 色的自主招生模式就显得尤为重要。

\section{1 国际经验}

作为世界高等教育最为发达的国家一 一美国和英国在高考招生制度方面各具特 色, 并对我国的高考招生制度未来改革有较 强的借鉴意义。

学术能力评估测试 (简称SAT) 是世界 著名的人才选拔考试, 由美国大学委员会主 办, 其成绩是包括美国在内的世界各国高中 生申请美国大学入学资格及奖学金的重要 参考, 它与美国大学入学考试 (ACT) 一起 被称为美国高考。与中国高考由国家教育主 管部门承担命题及阅卷工作不同的是, 美国 的考试组织工作由专业的非盈利教育机构

美国教育考试服务中心负责。SAT考试 
每年有 3 次, 其考试成绩有效期为 2 年, 并且 SAT成绩只是作为美国大学录取学生时参 考材料之一。美国各高校特别是常春藤联盟 的顶级名校都会在SAT考试基础上制定本 高校的录取标准, 对申请进入本高校就读的 学生通过面试来决定是否录取, 保证了学校 招生的自主性、独立性。其中面试既可以采 取现场面试, 也可以采取网络面试, 面试题 目由随即抽取的录取官从试题库中随机选 择, 但面试的问题大致与学生的日常生活、 研究兴趣、学科水平等紧密挂钩。经过面试, 一位学生可以参加多所学校的面试并被录 取, 学生最终选择一所高校就读。

英国作为世界高等教育强国与美国的 高考招生制度相近但也有所不同。英国同样 没有真正的全国统一高考, 而是将高考的职 能转化为高中课程考试, 简称A-Level考试, 英国高中课程的考试方法非常灵活, 学生可 以选择分阶段测试或者一次报考所学所有 课程。而且, 每门课程均有多次考试机会, 最终成绩以最好的一次计算。A-Level的考 试试题和中国高考试题一样, 由政府机构一 一英国国家考试局下属考试委员会统一命 题, 以确保考试的公正性。与美国相同的是, 英国各高校根据A-Level考试成绩确定入学 资格, 随后通过校内面试决定是否录取。面 试的问题也大多围绕学生的性格特征、兴趣 爱好、研究方向等进行。学生也有被多所高 校录取的机会和选择的权利[3]。

\section{2 国内经验}

自2003年开始, 我国在部分985、211 高校中实行了 “自主招生考试” 试点。考试 形式为 “笔试+面试”。高中毕业生通过考 核后, 可提前确定意向高校的录取名额, 并 在参加高考后享受降分优惠。根据教育部规 定, 自主招生人数不能超过试点学校年度本 科招生计划总数的 $5 \%$ 。

在高校自主招生考试中, 其中比较著名 的有北京大学、清华大学、浙大大学等985 名校联盟开展的联合笔试。也有复旦大学、 上海交通大学组织的针对上海等地考生单 独试点的自主招生。

其中复旦大学的自主招生考试一一复 旦水平测试, 也称千分考, 因其理论考试的 复杂性、全面性, 面试测试的规范性、严谨
性闻名, 值得各高校借鉴。在理论考试环节, 着重对学生综合素质的全面考察, 学生需在 3 个小时内做完 200 道选择题, 总计 1000 分, 考试压力较大。而在面试环节, 每个学生有 75 分钟的面试时间接受来自人文、自然科 学、基础科学和学生政治思想工作等学科的 5位专家的面试。为保证面试的公平和公正, 复旦大学采取了 “双盲” 措施, 暨参与测试 的学生事先不知到测试房间、不知道面试的 教授, 面试教授也不知道测试的房间号码和 学生姓名。此外, 复旦大学还专门成立了监 察组, 监督整个招生过程, 并设置录音机和 录音笔, 全程记录面试过程, 以便今后查验 [4]。

\section{3 地方工科类高校自主招生模式}

为适应高考招生制度改革由 “统一招 生” 到 “自主招生” 的趋势, 在充分参考国 际和国内的先进自主招生考试经验的基础 上,地方工科类高校应充分利用高中学业水 平考试模式, 尽早探索适应本校办学定位和 人才培养特色的自主招生模式。以上海工程 技术大学为例, 作为一所从未开展过本科阶 段自主招生的地方工科类高校将从以下几 个方面开展工作:

一是制定自主招生考试方案。学校应依 托学校招生委员会, 组成自主招生工作小 组, 利用校内多部门协作提前制定详细的学 校《自主招生测试方案》和参与考试岗位工 作实施细则, 为开展自主招生做好充分准 备。

二是明确自主招生考试环节。考试环节 包含了考试形式及科目、考试时间、考试地 点、报考资格、报考方法、考试规则、录取 方法等信息。其中, 由于高中学业水平考试 已经涵盖了高中所有课程, 因此学校可在考 试形式方面采用直接面试的形式, 以减少学 生的考试压力。在考试时间和考试地点的安 排上应遵循教育部及上海市教委的相关规 定, 安排在全国统一高考以后。在报考资格 方面，应充分借鉴美国及英国人才选拔经 验, 可按照不同专业的需求确定学生的报考 资格, 例如机械、汽车等工程类学科需要学 生掌握扎实的数学和物理知识, 在开展自主 招生时可要求学生报考时达到相应专业相 关学科的最低录取标准。而考试规则可以采 
取复旦大学自主招生考试的经验, 采取学生 和考官 “双盲” 制, 以保证考试的公平公正 性。

三是建设自主招生师资队伍。能否达到 选拔高素质应用型创新人才的招生目标一 方面取决于报考生源的综合素质, 更重要的 是取决于有多少能够发现 “千里马” 的 “伯 乐”。具备强大的师资队伍是高校顺利开展 自主招生考试的基础。目前, 受制于传统的 高考录取模式, 除艺术类、体育类外广大地 方工科类高校的专业教师几乎不参与学校 的招生过程。这就要求学校一方面要尽量选 择专业能力突出、沟通能力强、学科背景不 同的教师组建自主招生考试团队, 另一方面 要加大人力、物力、财力的投入, 积极开展 师资培训, 特别是测试目的、测试流程、测 试技巧方面的培训。此外, 学校还可以充分 发挥产学研协同优势, 通过在开展与行业协 同办学的专业招生时聘请相关行业企业或 的专家参与测试工作, 借助外脑共同选拔人 才。

四是建立自主招生考试题库。试题库的 建立应遵循依托专业、总量确保、分层建立、 内外结合、随机更新、注重保密的原则。依 托专业是指试题库的建设应以学院和专业 为主体, 每个学科或学科群应建立专属的试 题库, 以确保试题的科学性专业性。总量确 保是指试题库内的试题数量应满足多次考 试的数量需求。分层建立是指试题库内的试 题应按照不同难度系数进行整理分类, 在测 试时保证学生测试中的试题难度比例保持 一致。内外结合是指试题库的建立应邀请外 校乃至行业企业专家参与出题或进行评估, 从而保证试题的严谨性。随机更新是指试题 库在建立后应每年不定期地进行更新, 提高 试题与社会生产生活实际的联系度, 从而达 到考察学生发现问题、分析问题、解决问题 能力的目的。保密性是指应采用必要的程序 和技术手段确保试题库的安全, 所有参与自 主招生考试环节的教师都应签署保密承诺 书并接受保密教育。此外, 在测试过程中, 试题库的选择应充分利用信息化手段, 让学 生自主通过计算机随机抽取, 从而保证考试 的公平性和公正性。
五是加强自主招生考试监督。在组织建 设方面, 学校应成立以纪检监察部门为核心 的招生考试监督部门, 设置专门的监督电话 或监督邮箱, 建立相应的投诉调查反馈机 制。在测试过程监督方面, 可借鉴复旦经验 采取现场巡查监控和影像资料记录的方式, 对考试、面试、阅卷、录取等环节进行动态 监控, 发现问题及时处理。

\section{6. 结束语}

高等学校招生体制改革是一项关系到 国家命运前途和人民群众切身利益的重要 改革。地方工科类高校作为高等教育体系的 基础部分应充分认识改革发展的趋势、迎难 而上, 在参与改革的过程中正确把握自身定 位、找准发展方向, 为建立中国特色的高等 教育招生体制探索新路。

\section{References}

[1] Zhu Weiguo and Mei Zhen, Exploration on "Five-in-One" system of college entrance examination operating mechanism, Jiangsu High Education, Vol.2, pp.35- 37,2014.

[2] Fan Jiankang,On diversification and individualized education of college enrollment,education and professional,Vol.6,pp.33-34,2011.

[3] Dong Linbo and Feng Zhengjun, Exploration on college entrance examination reform under The Academic Test For The Ordinary Highschool Students, Education Research Monthly,Vol.3,pp.62-66,2013.

[4] Zheng Li, From the view of college alliance to the reform of self-determined admission, China Examinations, Vol.6,PP.52-57,2011.

[5] Feng Chenghuo,Reflections and explorations on the "Trinity" admission reform in Zhejiang province,Educational Research,Vol.10,PP.151-157,2014. 